Brit. J. vener. Dis. (1964), 40, 81.

\title{
SIGNIFICANCE OF SPIRAL ORGANISMS FOUND, AFTER \\ TREATMENT, IN LATE HUMAN AND \\ EXPERIMENTAL SYPHILIS*†
}

\author{
BY \\ PIERRE COLLART, LOUIS-JACQUES BOREL, AND PIERRE DUREL \\ WITH TECHNICAL ASSISTANCE FROM \\ M. AND F. DUNOYER, D. FERRANDEZ, AND J. MARIEN \\ Institut Alfred Fournier et Dispensaire de Salubrité, Paris
}

In previous publications (Collart, Borel, and Durel, 1962a, b), we have described the methods which we have used in a long series of experiments in late syphilis in rabbits and have announced our results. This study in animals led us to carry out the same investigations in humans with late syphilis and the preliminary results were published in the same year (Collart, Borel, and Durel, 1962b, c).

The present work includes certain additions, in particular details concerning the cerebrospinal fluid (CSF).

The overall results of our research have led us to the following conclusions:

(1) Penicillin treatment, if given late in the disease, of whatever dosage or duration, is unable to destroy all the treponemes which have been present in the organism for a long time.

(2) Persistence of treponemes in the tissues provides a satisfactory explanation for the continued presence of immobilizing antibodies after treatment.

(3) These treponemes have maintained their vitality.

(4) However, in the majority of cases, the treponemes appear to have lost all or a part of their virulence and exist in the tissues as commensal organisms.

(5) This host-parasite equilibrium could probably be upset by factors of which we are ignorant.

* Paper read by Dr Collart at a meeting of the MSSVD in London on November $29,1963$.

+ This Research was made possible by grants from the "Fondation Waksman pour le développement des études microbiologiques en France".
These conclusions are unexpected in view of the excellent practical results of penicillin in the treatment of the treponematoses. Therefore we should like to report new evidence and discuss the following points :

I. The value of morphological diagnosis.

II. The value of experiments in lymph-node transplants.

III. The observations made possible by reactivation due to cortisone.

\section{Value of Morphological Diagnosis}

Dark-ground examination is popular with clinicians for the examination of serum from a chancre or a mucous patch and also with the biologist who is working on experimental early syphilis. If the darkground examination is to be found positive, there must be an exudate which contains a suspension rich in $T$. pallidum. This is not the case in late syphilis, where silver-staining is the only method available, and where the organisms rarely have the appearance of $T$. pallidum as seen under the dark-ground microscope.

Levaditi and Vaisman (1945) have already shown that $T$. pallidum can be demonstrated by staining even after treatment with arsenic and penicillin, in the syphilomat of a rabbit, when examination by dark-ground microscopy was negative.

$\ddagger$ It should be pointed out that the word syphiloma is not employed in France for an acute orchitis but for the type of sclerotic nodule which forms towards the 2 nd or 3 rd week and persists for 3 to 5 months. 
Another important point is that the bacteriologist who is trying to make a diagnosis of a genital or buccal lesion always has in his mind the possible errors due to non-pathogenic spirochaetes. In examining smears from lymph nodes or of the CSF these sources of error do not seem to exist.

\section{(1) UNTREATEd SyPhiLIS IN RABbits}

To show that $T$. pallidum undergoes changes as the syphilitic infection ages, we propose to demonstrate the appearances in untreated syphilis in rabbits (intratesticular inoculation, Nichols strain, and staining by Dieterle's method).

(a) Fig. 1 shows the smears obtained from an acute orchitis on the 8th day with numerous $T$. pallida clearly outlined.

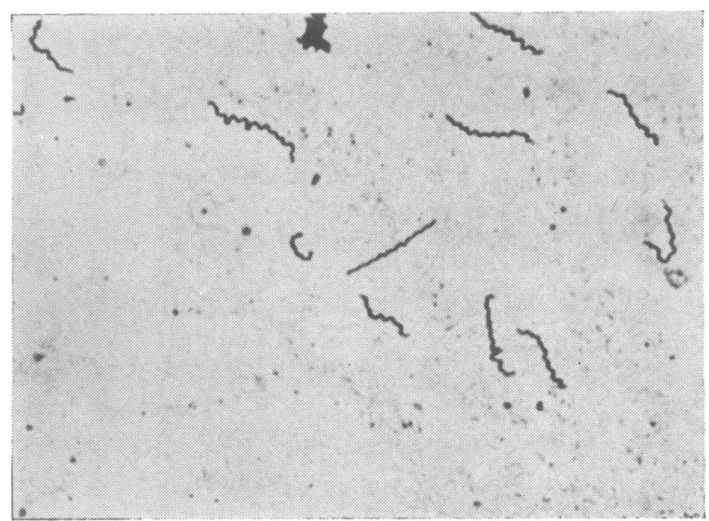

FIG. 1.-Aspirate from acute orchitis. Mixture of typical and less typical treponemes. $\times 1000$.

(b) As the infection ages, less typical organisms are found. Figs 2, 3, and 4 show examples from sclerotic testicular nodules which had been present from 56 to 120 days.

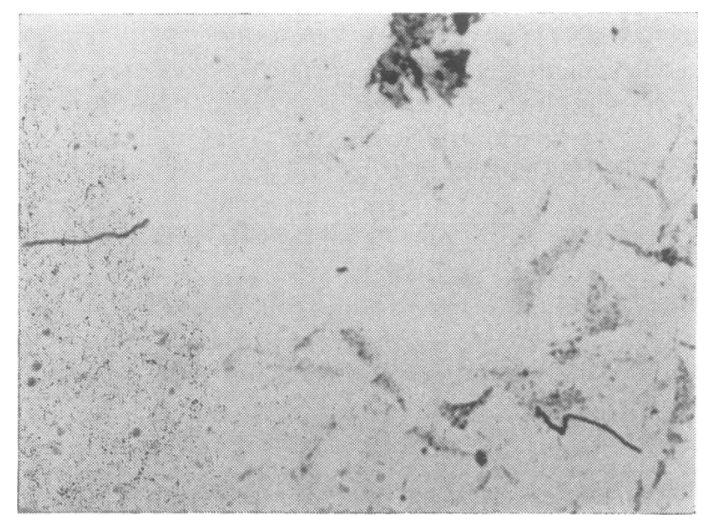

FIG. 2,-An untreated syphiloma of 56 days' duration. $\times 1000$.

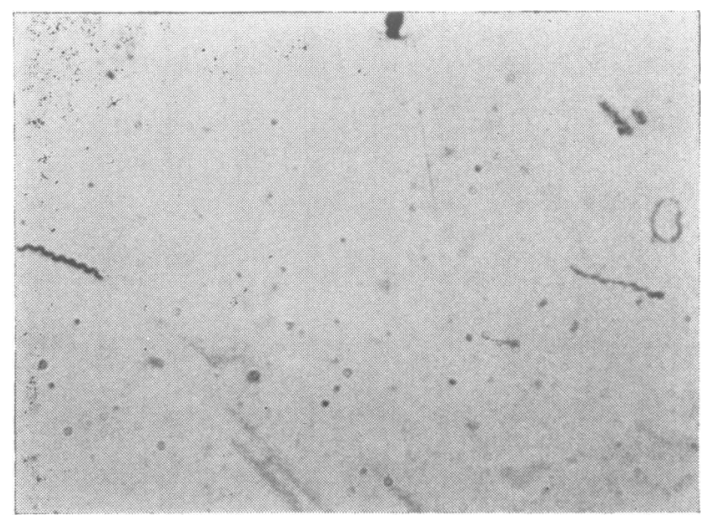

FIG. 3.-An untreated syphiloma of 112 days' duration. $\times 1000$.



FIG. 4.-An untreated syphiloma of 120 days' duration. $\times 1000$.

This may surprise those who rely on darkground microscopy; in fact, it has already been described but has been forgotten because the work was reported some years ago.

(c) Fig. 5 is a reproduction of a picture from Hoffmann, Hoffmann, and Mulzer (1927), but a description of similar forms is to be found in the works of Jacquet and Sézary (1907), Uhlenhuth and Mulzer (1913), Jahnel (1916, 1917a, b), Nichols (1914),

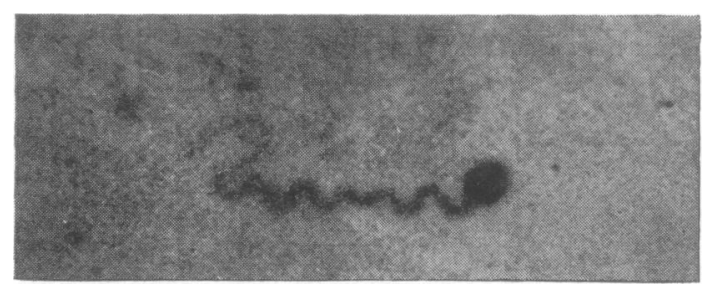

FiG. 5.-Atypical appearance of $T$. pallidum after Hoffmann, Hoffmann, and Mulzer (1927). Magnification unknown. 
Hauptmann (1919), Sprenger (1920), Aars (1928), etc.

The reviews of Wile (1916), of Brizard (1936), and of Sézary and Mollinedo (1944) describe in detail similar treponemes seen on staining in old lesions. These spiral organisms found in syphilitic tissue, have been considered by these authors to be T. pallida .

\section{(2) Observations on Specimens after Treatment}

(a) Smears from Popliteal Lymph Nodes of Rabbit.-The animals were treated with a dose of penicillin from 200,000 units to 6.5 mega units per $\mathrm{kg}$. about 2 years after inoculation and the lymph nodes were removed 8 to 12 months after treatment. The TPI was positive at this time and was still positive after a further 12 months.

Twenty rabbits were treated in this way and smears from the lymph nodes showed typical treponemes in eleven cases but in nine the morphology was less typical (Figs 6 to 8 ).

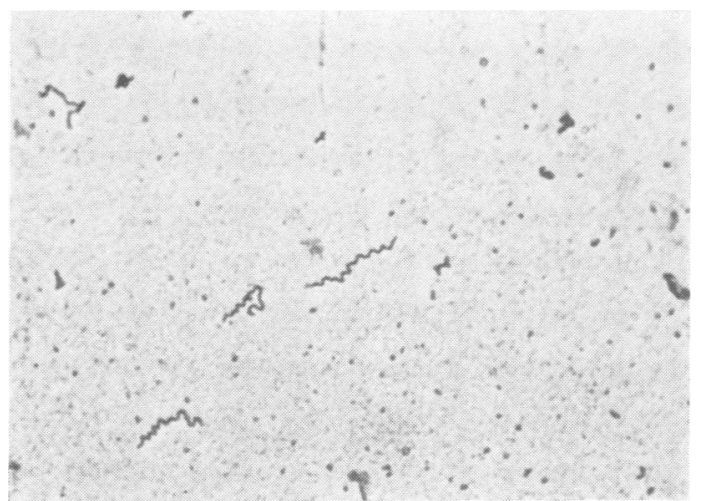

FIG. 6.-Popliteal lymphatic node of rabbit No. 28. Treated 2 years after infection with 200,000 units benzathine penicillin G. per $\mathrm{kg}$. Lymphatic node removed 293 days after completion of treatment. TPI titre 500 at that time.

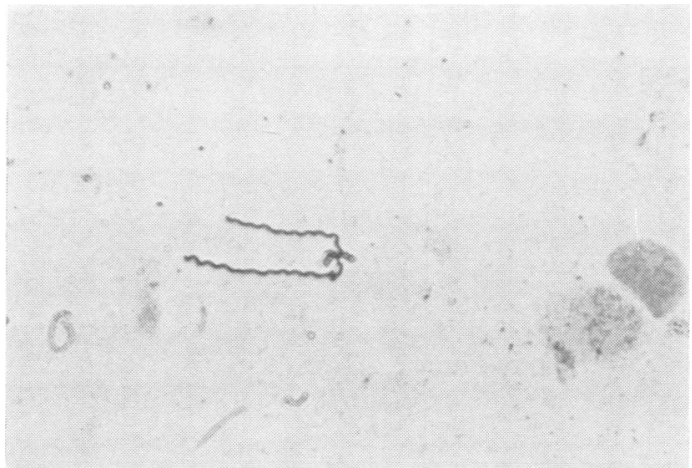

FIG. 7.-Popliteal lymphatic node of rabbit No. 46. Treatment similar; lymph node removed on the 296th day: TPI titre 1,800.

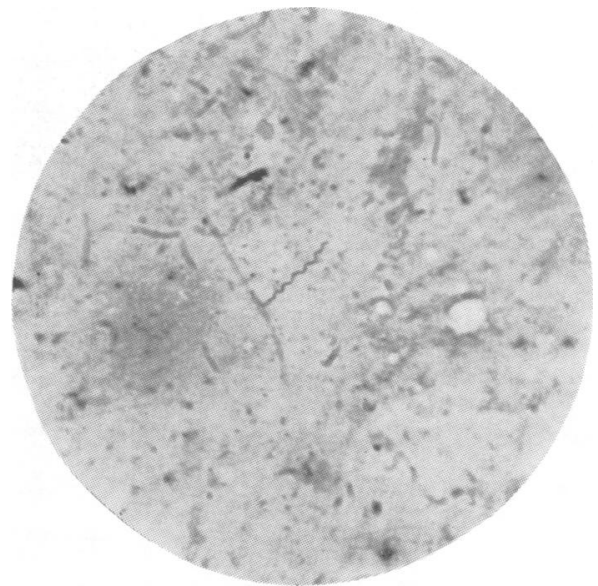

FIG. 8.-Popliteal lymphatic node of rabbit No. 79. Treated 22 months after infection with 6.5 mega units penicillin per $\mathrm{kg}$. Lymphatic node removed 6 months after treatment. TPI titre 100.

(b) Cerebrospinal Fluid of Rabbits. - The CSF of 5 of these rabbits, treated with 200,000 units penicillin per $\mathrm{kg}$., was examined and in all five cases staining showed more or less typical spiral organisms (Fig. 9).

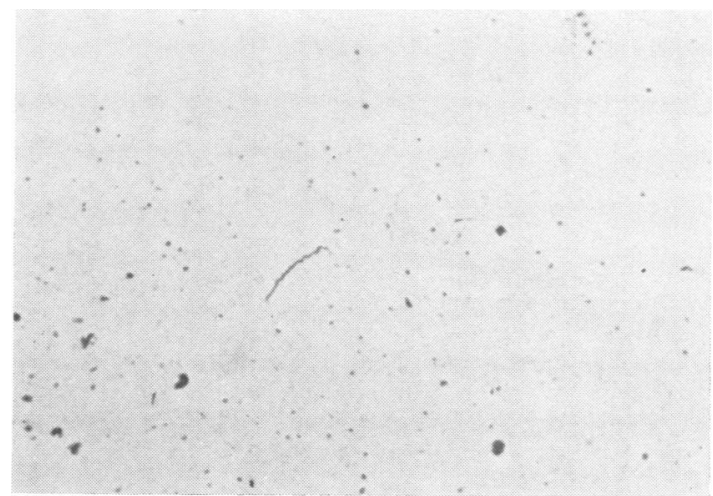

FIG. 9.-Cerebrospinal fluid of rabbit No. 15. Treated 2 years after infection with 200,000 units penicillin per $\mathrm{kg}$. Cerebrospinal fluid removed 13 months afterwards. TPI titre 400.

\section{(c) Smears of Human Inguinal Lymph Nodes:}

Case 1, a tabetic aged 64 years, had been treated with 151 mega units penicillin as well as bismuth and mercury. The TPI titre was 200 . The lymph node was removed 4 months after the last injection (Fig. 10, overleaf). This lymph node was transplanted and will be referred to later.

Case 2, a tabetic aged 59 years, had been treated with 50 mega units penicillin. The TPI was positive in the serum at a titre of 200 and was also positive in the CSF. A lymph node was removed 7 years after the last injection. A spiral organism which was not entirely typical was found (Fig. 11, overleaf), but after transplantation of the lymph node, typical $T$. pallida were found (see Fig. 15, below). 


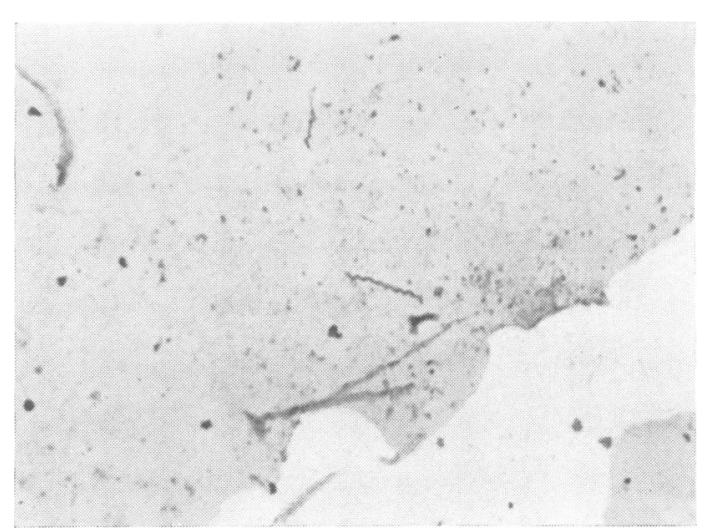

Fig. 10.-Case 1, a tabetic treated with 151 mega units penicillin. Lymphatic node smear ( $c f$. Fig. 14).

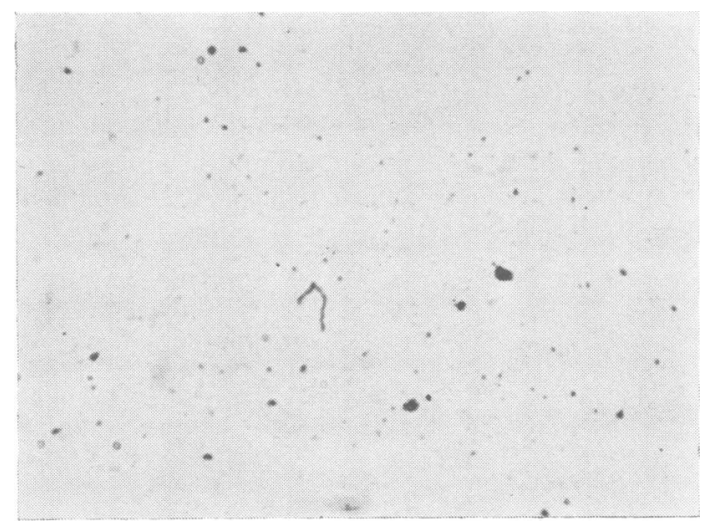

Fig. 11.-Case 2, a tabetic treated with 50 mega units penicillin Lymphatic node smear ( $c f$. Fig. 15).

Case 3, a tabetic aged 49 years, had been treated with 48 mega units penicillin. The TPI was positive at a titre of 600 . Fig. 12 shows a smear from a lymph node removed 9 months after the last injection.

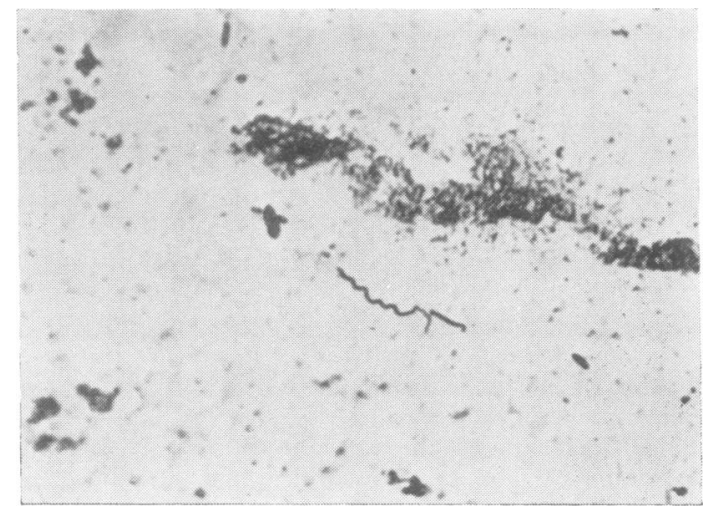

Fig. 12.-Case 3, a tabetic treated with 40 mega units penicillin Lymphatic node smear.
In all, the lymph nodes from twelve subjects were examined. In seven cases typical $T$. pallida were found and in five cases atypical forms were demonstrated.

\section{(d) Human Cerebrospinal Fluid:}

Case 4.-An example of what was found in latent syphilis after treatment with 10 mega units penicillin (Fig. 13). The TPI was positive with 100 per cent. immobilization.



FIG. 13.-Case 4, a case of latent syphilis. Smear of cerebrospinal fluid.

Further studies on the CSF are being undertaken.

At this point it should be stated that these spiral organisms do not always have the exact appearance of $T$. pallidum as found in a chancre and seen under dark-ground illumination. They are, however, in keeping with what we have seen, especially in late cases, in untreated syphilis in the rabbit and with what authors of the period 1910-20 regarded as $T$. pallidum. We have never seen anything resembling them in uninfected rabbits.* It should be stated, however, that it has not been possible to examine the lymph nodes or CSF of humans who were definitely free from syphilis, because each examination takes about 10 hours and it is difficult to gain permission to obtain human lymph nodes.

\section{Value of Lymph-Node Transplants}

When a fragment of the popliteal lymph node of a rabbit $A$ is inserted under the scrotum of a different rabbit $B$ (the recipient) and $B$ develops a syphiloma containing plenty of $T$. pallida, this is evidence that rabbit $\mathrm{A}$ was infected with syphilis and that the

* Our rabbit house has not been infected with $T$. cuniculi throughout the whole of our work and as $T$. cuniculi is not pathogenic to man, this cannot explain the organisms found in our patients. 
infection was virulent. This test, however, is only of relative value in cases of late syphilis.

\section{(1) UNTREATEd RabBits}

The following observations were made at different times in untreated syphilitic rabbits.

(a) At the beginning of our work, we inoculated both testicles of fifty rabbits with $\mathbf{5 0}$ million $T$. pallida. In each case bilateral orchitis developed. At an average period of 18 days later, a syphiloma had developed in 48 animals. The other two had a persistently positive TPI test and were considered to have latent syphilis.

(b) 18 to 24 months after infection, a popliteal lymph node from 38 of these rabbits, which were still untreated, was implanted subscrotally into 38 different animals. 29 of them developed a syphiloma, with $T$. pallida present on dark-ground examination, but these appeared slowly in an average period of 40 days. Two rabbits did not develop lesions, but the TPI test became positive on the 116th and the 154th day respectively. Seven were considered to be negative despite a transient rise in the doubtful zone of specific immobilization in the TPI test.

(c) At the 36th month of the experiment there were 26 rabbits and a new lymph-node transplant was performed from six of these animals, which were being used as untreated controls. (Twenty of the rabbits had been treated at the 24th month.) The results of these six transplants were even less satisfactory. Two recipient animals developed minimal and transient lesions at the area of inoculation and it was 4 months before their TPI tests reached 80 and 100 per cent. immobilization. The four other recipients showed no lesions and their TPI tests remained negative.*

Thus, in untreated experimental syphilis, there is a progressive gradual lessening of virulence with the duration of the infection. It is impossible, therefore, to rely on lymph-node implants alone to confirm the bacteriological sterilization of a living organism.

\footnotetext{
* The TPI test was systematically performed on every rabbit entering the rabbit house, including these six, and was always negative at this stage.
}

This is, in fact, a general law as stated by Gastinel (1957):

"There is no correlation between the pathogenicity of an organism isolated during the course of an illness and its experimental pathogenicity in an animal".

\section{(2) Treated Rabits}

(a) The experience of Chesney and Kemp (1925) illustrates the failure of lymph-node transplants in long-standing syphilis and also shows that virulent treponemes can survive treatment which is considered to be active. During the 6th month of their syphilis, six rabbits were treated with arsenobenzene at a dose of $10 \mathrm{mg}$. per $\mathrm{kg}$. once a week for 6 weeks. The lymph-node transplants were all negative, but 40 days after completing the arsenic therapy, one rabbit developed keratitis with $T$. pallida present. The pulverized cornea produced a syphiloma in a recipient rabbit.

(b) In our own experience we have been able to demonstrate that failure of the lymph-node transplants is almost always the rule after penicillin treatment:

One year after treatment, that is to say, in the 36th month of the disease, twenty rabbits were available from those which had been treated with 200,000 units penicillin per $\mathrm{kg}$. The second popliteal lymph-node was used for the transplant. In all these cases, it should be remembered, more or less typical spiral organisms were found in the donor rabbits. However, only a single recipient reacted to the transplant. It did not produce a lesion but the TPI test became positive, with 80 per cent. specific immobilization, in the 5th month and $T$. pallida was found in the node. The nineteen other recipients remained clinically negative but, in eight of them the smear of their popliteal lymph-nodes showed spiral organisms on staining, and in four of these eight animals the TPI test, which had previously been negative, showed a transitory weak increase in immobilization, a fact which we should like to note but do not wish to interpret at present.

Thus, the virulence becomes spontaneously attenuated in untreated rabbits, but becomes even more attenuated in treated animals. When, as in these cases, the lymph-node transplants are negative, it cannot be concluded that infectivity is absent 
because negative transplants also occur in untreated animals.

\section{(3) Human Cases}

Despite the reservations stated above, we used the method of lymph-node transplant whenever possible in human cases. Here we came up against another difficulty, namely the adaptation of a human strain to the rabbit. It is well known that, even when darkground examination shows large numbers of $T$. pallida in a human lesion, such as a chancre, infection of a recipient rabbit by such an inoculum is far from being the rule.

In the cases of five patients who had received a large amount of treatment, we were able to undertake an inguinal lymph-node transplant into fresh rabbits. In three of the five cases thickening of the tunica vaginalis was noted; this was minute, its size varying between that of a grain of rice and that of a lentil. Specimens taken from the 14th to the 194th day after inoculation showed spiral organisms, which it was difficult not to call $T$. pallida.

A small piece of an inguinal lymph node from Case 1 (above) was transplanted subscrotally into a rabbit and aspiration of the graft was positive on several occasions, especially on the 42 nd day (Fig. 14).

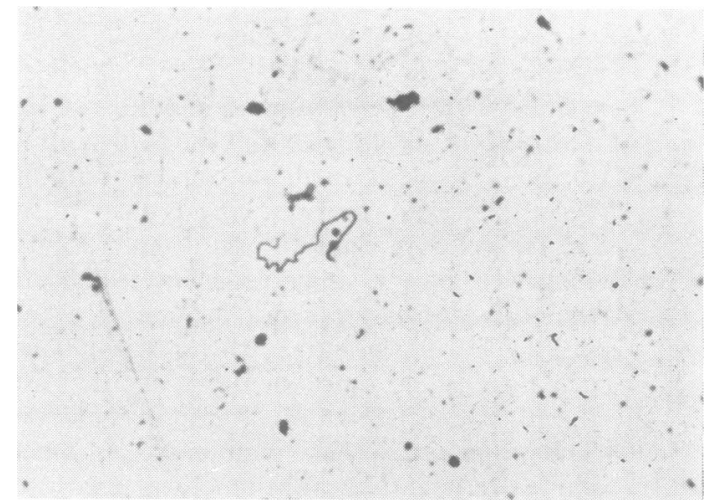

FIG. 14.-A fragment of the inguinal lymphatic node from Case 1 was inserted under the scrotum of rabbit No. 184. Smear of graft 42 days after insertion.

The same applied to Case 2 (above) and aspiration of the graft on the 113th day showed morphologically typical $T$. pallida (Fig. 15).

The third example was that of Case 5 ; in this case the lymph-node preparation showed a less typical form of organism.

\section{Reactivation by CoRtisone}

In view of the unreliable results of lymph-node

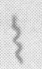

FIG. 15.-Same operation from Case 2 to rabbit No. 163. Smear of graft 113 days after insertion.

transplants in late syphilis, can further information be obtained by "reactivation"?

McLeod and Magnuson (1956) have shown that cortisone can, on occasion, cause lesions of late syphilis to appear in rabbits with latent syphilis, especially in cases of scar tissue. Into twelve rabbits, which had been treated with 200,000 units penicillin per kg. 2 years after infection, and which showed a positive TPI test, we injected 200 to $250 \mathrm{mg}$. cortisone in 10 days. Two of them developed lesions, which resembled very closely those described by Brown and Pearce (1920) in untreated experimental syphilis, in the area of scar tissue around the identification clips on their ears.

Fig. 16 (opposite) shows the picture taken by Brown and Pearce and Fig. 17 (opposite) the lesion produced in one of our two rabbits. The appearances are identical and resemble the circinate and infiltrated lesions of tertiary syphilis in humans.

As is usual in tertiary syphilis in humans, biopsy showed non-specific histological changes but the smear showed a spiral organism (Fig. 18, opposite).

It is interesting that, before the cortisone was administered, the popliteal lymph nodes of these two rabbits were transplanted into fresh animals and these transplants remained negative. This is another example of the unreliability of lymph-node transplants.

\section{DisCUSSION AND INTERPRETATION OF THE RESULTS}

\section{(1) Are the organisms really Treponema pallida?}

We found spiral organisms in the lymph nodes and the cerebrospinal fluid of rabbits and of treated patients, which do not always show the typical morphological appearance of $T$. pallida as seen in a chancre or in an acute orchitis. These organisms are 


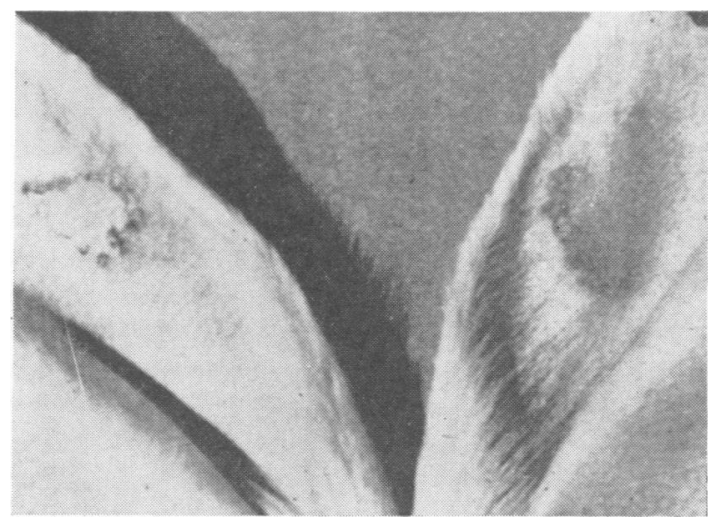

FIG. 16.- Photograph of an illustration from Brown and Pearce (1920), showing late syphilis of the ears in an untreated rabbit.

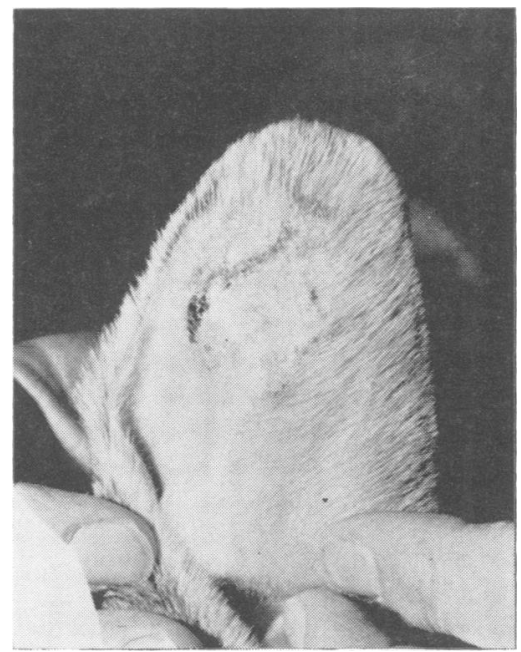

FIG. 17.-Rabbit No. 12, treated 2 years after infection with 200,000 units benzathine penicillin G. per kg., and given $200 \mathrm{mg}$. cortisone acetate 1 year later. Ear lesion appeared 2 months after the cortisone therapy.

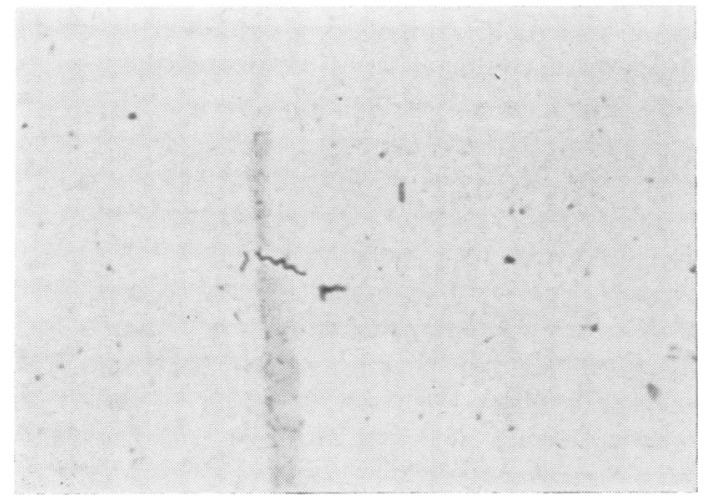

FIG. 18.-Smear of biopsy of ear lesion of rabbit No. 12. the same as those seen in late untreated experimental syphilis and are called $T$. pallida by numerous authors whose scattered publications do not seem to have attracted much attention.

\section{(2) Immunofluorescence}

It would have been helpful, for the bacteriological diagnosis, if these spiral organisms could have been demonstrated by immunofluorescence. In practice this is extremely difficult because of the extreme rarity of these organisms in the smears. The examination takes several hours, a fact which is not without its disadvantages, and it is well known that the brilliance soon loses its intensity. The chance of finding a fluorescent complex is, therefore, extremely small. On one occasion, however, on a smear of the CSF, a spiral organism showed the phenomenon of fluorescence.

\section{(3) Have the T. pallida conserved their vitality?}

Levaditi and Vaisman (1945) observed $T$. pallida in lesions of rabbits 10 days after treatment with 40,000 units penicillin per $\mathrm{kg}$. and thought that they were the "dead bodies" of $T$. pallida. We have found them 12 months or longer after treatment in animals and up to 12 years after treatment in men. It seems, therefore, that they have preserved a certain degree of vitality, otherwise they would have been lysed and eliminated.

Moreover, spiral organisms would not be found several weeks or months later in recipient animals if the T. pallida of the donors had lost their faculty of reproduction, nor would they have been able to cause the TPI test to become positive to 80 per cent. of specific immobilization in one recipient out of twenty. Lastly, cortisone would not have been able to reactivate organisms which had lost their vitality.

\section{(4) Have the T. pallida lost their virulence?}

The material used for the lymph-node transplants was certainly not rich in organisms but we know that even an inoculum which is very poor in treponemes can succeed, even in exceptional circumstances. In our experience, lymph-node transplants carried out near to the 36th month after infection nearly always fail in untreated and, even more so, in treated animals and also in humans. When there was a positive response, it was only very minimal by comparison with what is seen in early syphilis. It must be admitted that these organisms have lost all or part of their virulence.

These observations are in keeping with the views of biologists on virulence, Dubos (1945), for example, 
is quoted by Gastinel (1957) as saying:

"Virulence is not a permanent and intrinsic property of a given species. It expresses only the capacity of a given strain to produce at a certain moment in its growth, a pathological state in a particular host, when it is introduced into that host under certain limited conditions."

If, on the one hand, the very frequent passage of the Nichols strain from one rabbit to another for several years has increased its reproductive capabilities and considerably increased its virulence, on the other hand its assumption of a latent state for a very long period in a single host has been able progressively to produce this same property.

Without doubt, it is an analogous phenomenon which explains why inoculations of fragments from the brain of general paralytics have nearly always been unsuccessful. Forster (1913) concluded, after several failures, that the $T$. pallida in cases of genuine paralysis of the insane were "modified biologically". Noguchi (1913) wrote:

"The infectiousness of general paralysis is weak and the virulence of the spirochaete from this source to rabbits is also weak."

\section{(5) Is this loss of virulence permanent?}

Our observations in two cases after cortisone administration make us cautious. The influence of cortisone therapy in experimental syphilis merits further study to complete the picture.

(6) Is the persistence of T. pallida after treatment unique to this species?

Probably not; and what we call cure, in a clinical sense, probably does not correspond to total bacteriological destruction. Eagle (1952), who was kind enough to examine our specimens and showed interest in them, reminded us of his observations when he studied the action of penicillin in mice infected with haemolytic streptococci and its relationship to the duration of the infection. After a certain time, penicillin was no longer effective, even in very high doses, although the organism remained sensitive in vitro. Eagle considers that this may be due to the localization of the infection in small foci which the antibiotic cannot easily reach where the germs become modified, on the one hand, because nutritive material does not readily reach the area and, on the other, because the accumulation of toxic products from the bacteria hinders their growth and diminishes their sensitivity to antibiotics. It is generally agreed that, in numerous infections, antibiotic therapy acts more effectively when the illness is in an active phase. The condition of bacteriological quiescence is perhaps what we call clinical cure, but it is also a state which explains the small effect of a new course of treatment.

\section{SUMMARY}

The authors draw attention to their publications in 1962 and underline the following points:

(1) In untreated experimental syphilis, as the infection grows older, the morphology of $T$. pallida found in smears from lymph nodes becomes progressively less and less typical. This fact should be remembered when studying the spiral organisms found, after treatment, in late syphilis in the rabbit or in man in the lymph nodes and the cerebrospinal fluid. It is probable that they are, in fact, $T$. pallida, and their presence explains the persistence of positive serological tests.

Immunofluorescent techniques cannot at present help to confirm the bacteriological diagnosis for technical reasons.

(2) In untreated experimental syphilis, lymph-node transplants to fresh animals are progressively less and less successful as the infection ages. In animals and in men treated late in the disease, the failure of these transplants does not necessarily exclude the persistence of some $T$. pallida.

(3) Cortisone can sometimes reactivate latent syphilis in rabbits. Two rabbits out of twelve which had been treated and then given cortisone presented the classical lesions of late syphilis. These observations appear to be evidence of persistence of vitality of the $T$. pallida.

It seems then that in late syphilis penicillin and the other classical medicaments are unable to destroy all the $T$. pallida. The $T$. pallida appear to preserve their vitality but to lose all or part of their virulence. It also seems likely that the bacteriological equilibrium, which corresponds probably to what we call clinical cure, can be upset by factors which are as yet unknown.

We are grateful to M. J. Rivière for the photomicrographs which illustrate this article.

\section{REFERENCES}

Aars, C. G. (1928). Ned. Mschr. Geneesk., 15, 129.

Brizard, A. (1936). Thèse de Paris.

Brown, W. H., and Pearce, L. (1920). J. exp. Med., 32, $445,473,497$.

Chesney, A., and Kemp, J. E. (1925). Jbid., 42, 33.

Collart, P., Borel, L.-J., and Durel, P. (1962a). Ann. Inst. Pasteur, 102, 596, 693. (1962b). Ibid., 102, 953.

(1962c). Ann. Derm. Syph., 89, 488. 
Dubos, R. J. (1945). "The Bacterial Cell". Harvard University Press, Cambridge, Mass.

Eagle, H. (1952). Amer. J. Med., 13, 389.

Forster, E. (1913). Neurol. Zbl., 32, 1523.

(1931). Z. ges. Neurol. Psychiat., 133, 322.

Gastinel, P., and Others (1957). "Précis de bactériologie médicale", 2nd ed. Masson, Paris.

Hauptmann, A. (1919). Mschr. Psychiat. Neurol., 45, $59,165$.

Hoffmann, E., Hoffmann, E., and Mulzer, P. (1927). "Morphologie und Biologie der Spirochaeta pallida", in "Handbuch der Haut- und Geschlechts Krankheiten", ed. J. Jadassohn, band 15, teil 1, p. 29. Springer, Berlin.

Jacquet, L., and Sézary, A. (1907). Bull. Soc. méd. Hôp. Paris, 3e sér., 24, 114.

Jahnel, F. (1916). Arch. Psychiat. Nervenkrank., 56, 798. (1917a), Ibid., 57, 382.

(1917b). Derm. Z., 24, 604.

Levaditi, C., and Vaisman, A. (1945). Bull. Acad. Méd. (Paris), 129, 394.

McLeod, C. P., and Magnuson, H. J. (1956). J. Immunol., 76, 373.

Nichols, H. J. (1914). J. exp. Med., 19, 362.

Noguchi, H. (1913). Münch. med. Wschr., 60, 737.

Sézary, A., and Mollinedo, R. (1944). "Encyclopédie méd.-chir.", 3033A, 7; 3303B, 4.

Sprenger, G. (1920). Arch. Psychiat. Nervenkrank., 61, 479.

Uhlenhuth, P., and Mulzer, P. (1913). Zbl. Bakt. Abt. I, Referate, Bd 57, Beiheft, p. 158.

Wile, U. J. (1916). J. exp. Med., 23, 199.

Formes spiralées trouvées après traitement dans la syphilis tardive du lapin et chez l'homme

RÉSUMÉ

Les auteurs rappellent leurs publications de 1962 et insistent sur les points suivants:
(1) Dans la syphilis expérimentale non traitée, au fur et à mesure que l'infection vieillit, la morphologie des Tp décelés sur les frottis de ganglions devient de moins en moins typique. On doit donc prendre en considération les formes spiralées trouvées, après traitement, dans la syphilis tardive du lapin ou chez l'homme (ganglions et liquide spinal). Il est vraisemblable qu'il s'agit bien de Tp, dont la présence explique l'irréductibilité de la sérologie.

L'immuno-fluorescence, pour des raisons pratiques, ne peut servir, actuellement, à renforcer le diagnostic bactériologique.

(2) Dans la syphilis expérimentale non traitée, les transferts ganglionnaires à des animaux neufs réussissent de plus en plus rarement, au fur et à mesure que l'infection vieillit. Chez l'animal et chez l'homme traités très tardivement, l'échec du transfert n'exclut donc pas forcément la persistance de quelques Tp.

(3) La cortisone peut quelquefois réactiver une syphilis latente chez le lapin. Deux lapins sur 12 qui avaient été traités et qui avaient reçu de la cortisone ont présenté des lésions du type classique de la syphilis tardive. Ceci semble pouvoir être accepté comme le témoignage de la persistance de la vitalité des Tp.

Il apparaît donc:

—que la pénicilline (et les autres médicaments classiques) est incapable de détruire tous les Tp au cours de la syphilis tardive;

—que ceux-ci ont conservé leur vitalité;

-qu'ils ont perdu tout ou partie de leur virulence;

-que l'équilibre parasites/hôte (que correspond sans doute à ce qu'on appelle guérison clinique) peut être rompu par des facteurs que nous ne connaissons pas. 